\title{
Association between urinary symptoms and quality of life in HTLV-1 infected subjects without myelopathy
}

\author{
Rosana Andrade, Davi Tanajura, Deise Santana, Dislene dos Santos, Edgar M. Carvalho \\ Department of Physiotherapy, (RA, DS, DS) and Department of Immunology (DT, EMC), Professor Edgard \\ Santos, University Hospital Complex, Federal University of Bahia, Salvador, Bahia, Brazil
}

\section{ABSTRACT}

Objective: To investigate the relationship between urinary symptoms and quality of life of patients infected with HTLV-1.

Materials and Methods: This is a cross-sectional study that enrolled individuals with HTLV-1 positive serology from February 2010 to March 2011. Participants were HTLV-1 infected subjects followed in the HTLV-1 clinic of the University Hospital in Salvador, Bahia, Brazil. Patients with HTLV-1 associated myelopathy / tropical spastic paraparesis (HAM/TSP), who had evidence of other neurological diseases, diabetes mellitus or were pregnant were excluded from the study. The questionnaire SF-36 was used to evaluate quality of life and the questionnaire $\mathrm{OAB}-\mathrm{V} 8$ was used to evaluate urinary symptoms. Results: From the 118 individuals evaluated, 50 (42.4\%) complained of urinary symptoms and 68 (57.6\%) did not. Most participants were females. There was no difference between the groups regarding demographic variables. The group with symptoms showed significantly lower scores in all domains of the SF-36 questionnaire. The domains with greatest differences were vitality and general health state.

Conclusions: Urinary symptoms negatively influence the quality of life of individuals infected with HTLV-1.

\section{ARTICLE INFO}

\section{Key words:}

Quality of Life; Human T-

-lymphotropic virus 1; Lower

Urinary Tract Symptoms;

Urinary Bladder, Neurogenic

Int Braz J Urol. 2013; 39: 861-6

Submitted for publication: January 29, 2013

Accepted after revision:

November 09, 2013

\section{INTRODUCTION}

The human T-lymphotropic virus type 1(HTLV-1) was the first human retrovirus isolated (1). It is estimated that 11 to 20 million people are infected worldwide (2). Regions such as Japan, Africa, the Caribbean Islands and South America have the highest incidence of infection (3). In Brazil, Bahia is one of the states with the highest prevalence, totalizing 9.4 individuals per 1,000 blood donors (4). Salvador, the state's capital, is the city with the highest prevalence of infected individuals, with $1.76 \%$ of the resident population being affected by the virus (5).

Several clinical conditions have been attributed to this virus with HTLV-1 associated mye- lopathy / tropical spastic paraparesis (HAM/TSP) and the adult $\mathrm{T}$ cell lymphoma/ leukemia (ATLL) (6) being the most important forms of disease. The lifetime prevalence of these two clinical entities is about 5\%. However, other clinical and neurological manifestations have been linked to the virus. Among them, the neurogenic bladder has significant prevalence $(7,8)$. Urinary complaints are found in virtually $100 \%$ of individuals with HAM/ TSP and in about $14 \%$ of HTLV-1 individuals without HAM/TSP. The main symptoms are urgency, incontinence and nocturia (8-10).

These urinary manifestations can be an important sign of the virus' evolution and increased severity of the viral infection and are important signs of incipient myelopathy. 
Urinary symptoms in individuals infected by the virus have been shown to lead to social isolation and depression $(9,11)$. It is important to determine the effect of these symptoms in the well-being of affected individuals and to assess their general health status in order to prevent disturbances in disease treatment and to improve clinical outcomes. Thus, the objective of this study was to verify the association between quality of life and urinary symptoms in patients infected with HTLV-1.

\section{MATERIALS AND METHODS}

\section{Study design}

This is a cross-sectional study with 118 non-consecutive HTLV-1 infected individuals followed at the HTLV Multidisciplinary Ambulatory of the Immunology Service, Professor Edgar Santos University Hospital Complex / Federal University of Bahia (COM-HUPES/UFBA), in Salvador, Bahia, Brazil, from February 2010 to March 2011. This outpatient service has an ongoing cohort since 2004 and semi-annual to annual follow-up is carried out for each patient.

\section{Inclusion and exclusion criteria}

Individuals over 18 years of age with positive HTLV-1 serology determined by ELISA (Cambridge Biotech, Worcester, MA) and confirmed by Western-blot (HTLV Blot 2.4, Genelabs, Science Park Drive, Singapore) who had been submitted to urological and neurological evaluation were included in the study. Individuals with confirmed HAM/TSP and other neurological diseases that are associated with urinary symptoms (stroke, Parkinson's disease and multiple sclerosis), diabetes mellitus and pregnant women were excluded from the study. The diagnosis criteria for HAM/ TSP was based on the Osame Motor Dysfunction Scale (OMDS) $\geq 1$ and presence of HTLV-1 in the liquor as recommended by the World Health Organization (WHO).

\section{Instruments}

In order to evaluate quality of life in the study participants, the multidimensional questionnaire 36-item Short-Form Health Survey (SF-36) was used. This questionnaire analyzes the physical and mental components defined by four domains each. The physical components are physical functioning, role limitations due to physical problems, bodily pain, and general health. The mental components are vitality, social functioning, role limitation due to emotional problems and mental health (12). The value obtained for each domain varies in a scale from 0 to 100 , with 0 being the worse state and 100 the best.

Urinary symptoms were established based on answers participants gave to the Overactive Bladder Questionnaires - simplified (OAB-V8), an instrument validated to diagnose the presence of overactive bladder (13). Selected participants were placed in groups according to the presence or absence of urinary symptoms as defined by the $\mathrm{OAB}$ -V8 questionnaire.

\section{Statistical analysis}

Variables in tables contain continuous data presented as mean \pm SD and categorical data presented as absolute and relative (\%) frequencies.

The t-test for independent samples was used to compare continuous variables and the Chi-square test was used to compare proportions between the two groups. A logistic regression analysis was performed in order to determine the relationship between quality of life and urinary symptoms.

Statistical significance was established at $p \leq 0.05$. The SPSS version 20.0 was used for statistical analysis.

\section{Ethical aspects}

All participants signed an Informed Consent and the study was approved by the Ethics Committee of the COM/HUPES/UFBA.

\section{RESULTS}

A total of 118 HTLV-1 infected subjects were included in the study. Fifty individuals (42.4\%) had urinary symptoms and 68 (57.6\%) had no urinary symptoms. The mean age of the sample was $53.8 \pm$ 12.12 years, mainly females (58.5\%). The symptoms identified in the urinary symptoms group were nocturia in 44 participants (84.6\%), urgency 33 (63.5\%), 
increase in urinary frequency in 28 (53.8\%), urinary incontinence in 27 (51.9\%), urge-incontinence in 22 (42.3\%), polyuria in $4(7.7 \%)$, enuresis in $2(3.8 \%)$, and urinary effort in 1 (1.9\%).

The sociodemographic characteristics of the subjects without urinary symptoms are shown in Table-1. In both groups, the majority of participants had basic schooling, were of mixed race/ethnicity, and had income levels between 1 and 3 minimum Brazilian salaries (545.00 Brazilian reais per month, or, at the concurrent exchange rate at the time of study, US\$336.00 or €233.56). There were no significant differences between both groups regarding the sociodemographic characteristics.

Table 1 - Sociodemographic characteristics of the HTLV-1 infected subjects with HTLV-1 with and without urinary symptoms.

\begin{tabular}{|c|c|c|c|}
\hline & $\begin{array}{l}\text { With Urinary Symptoms } \\
\qquad N=50\end{array}$ & $\begin{array}{l}\text { Without Urinary Symptoms } \\
\qquad N=68\end{array}$ & $p$ \\
\hline Age & $55.02 \pm 11.50$ & $53.06 \pm 12.57$ & $0.38^{\mathrm{a}}$ \\
\hline Gender & & & $0.64^{b}$ \\
\hline Female & $28(56.0)$ & $41(60.0)$ & \\
\hline Male & $22(44.0)$ & $27(40.0)$ & \\
\hline Schooling & & & $0.66^{b}$ \\
\hline Illiterate & $1(2.0)$ & 0 & \\
\hline Basic Education & $31(62.0)$ & $42(61.8)$ & \\
\hline Pre-college & $16(32.0)$ & $22(32.4)$ & \\
\hline University & $2(4.0)$ & $4(5.9)$ & \\
\hline Marital Status & & & $0.90^{\mathrm{b}}$ \\
\hline Single & $9(18.4)$ & $15(22.1)$ & \\
\hline Married & $29(59.2)$ & $37(54.4)$ & \\
\hline Divorced & $6(12.2)$ & $10(14.7)$ & \\
\hline Widowed & $5(10.2)$ & $6(8.8)$ & \\
\hline Skin color & & & $0.35^{b}$ \\
\hline White & $6(12.0)$ & $3(4.4)$ & \\
\hline Mixed race/ethnicity & $30(60.0)$ & $41(60.3)$ & \\
\hline Black & $14(28.0)$ & $23(33.8)$ & \\
\hline Did not inform & 0 & $1(1.5)$ & \\
\hline Family income & & & $0.16^{b}$ \\
\hline$<1$ minimum wage ${ }^{1}$ & $10(20.0)$ & $6(8.8)$ & \\
\hline 1 minimum wage & $17(34.0)$ & $18(26.5)$ & \\
\hline 2 to 3 minimum wages & $17(34.0)$ & $34(50.0)$ & \\
\hline$>4$ minimum wages & $6(12.0)$ & $10(14.7)$ & \\
\hline
\end{tabular}

The continuous variable (age) is presented as mean \pm standard deviation while data are presented as absolute and relative (\%) groups.

a independent $\mathrm{T}$ test; ${ }^{\mathbf{b}}$ Chi-square test.

${ }^{1}$ One minimum wage is about US\$336.00 or $€ 233.56 /$ month. 
When the SF-36 questionnaire was applied, all variables tested showed significant differences in the score means between groups. The domains with the highest negative influence were vitality (OR 4.23), general health state (OR 3.81) and limitation due to physical aspects (OR 3.00) (Table-2). quality of life in the domains of general health perception, social relations, and sleep and mood aspects, in addition to limitations in their activities of daily life (14). However, the study was limited due to heterogeneity in disease stage classification of the study population.

Table 2 - Quality of life of the studied sample according to the groups with and without urinary symptoms.

\begin{tabular}{lccccc}
\hline SF-36 & $\begin{array}{c}\text { With Urinary } \\
\text { Symptoms } \\
\mathrm{N}=50\end{array}$ & $\begin{array}{c}\text { Without Urinary } \\
\text { Symptoms } \\
\mathrm{N}=68\end{array}$ & $\mathrm{p}^{\mathrm{a}}$ & OR (IC 95\%) & $\mathrm{p}^{\mathrm{b}}$ \\
\hline Functional capacity & $64.90 \pm 31.15$ & $81.01 \pm 27.18$ & $<0.01$ & $2.43(1.01-5.86)$ & 0.04 \\
Limitation (physical aspects) & $52.50 \pm 49.63$ & $78.46 \pm 39.28$ & $<0.01$ & $3.00(1.36-6.60)$ & $<0.01$ \\
Pain & $51.60 \pm 30.06$ & $69.02 \pm 27.92$ & $<0.01$ & $2.94(1.33-6.47)$ & $<0.01$ \\
General health state & $47.46 \pm 17.74$ & $60.59 \pm 19.78$ & $<0.01$ & $3.81(1.74-8.35)$ & $<0.01$ \\
Vitality & $56.10 \pm 23.91$ & $72.46 \pm 24.69$ & $<0.01$ & $4.23(1.86-9.60)$ & $<0.01$ \\
Social aspects & $73.34 \pm 25.35$ & $84.34 \pm 24.64$ & 0.02 & $2.70(1.02-7.16)$ & $<0.01$ \\
Limitation (emotional aspects) & $56.66 \pm 47.26$ & $78.88 \pm 38.60$ & $<0.01$ & $2.55(1.14-5.70)$ & $<0.01$ \\
Mental health & $61.58 \pm 22.25$ & $73.43 \pm 23.58$ & $<0.01$ & $2.22(0.91-5.37)$ & $<0.01$ \\
\hline
\end{tabular}

a independent T test; ${ }^{\mathbf{b}}$ univariate logistic regression relating items of the questionnaire of quality of life with the presence of urinary symptoms. In codifying variables: 1 = low quality of life $($ score $<50) 0=$ adequate quality of life $($ score $>50)$.

\section{DISCUSSION}

From all items evaluated in the questionnaire SF-36, general health state and vitality were independently associated with quality of life in the group with urinary complaints. The consistent relationship of these factors with quality of life reflects how these individuals feel in relation to life and health. It is also a reflection of the limitations their symptoms have on the performance of their activity of daily life as well as their professional and social activities. In addition, it reflects the impact of their disease on their emotional state and their quality of life.

A previous study that compared the impact of urinary incontinence in the quality of life of women infected with HTLV-1 with uninfected women showed that infected women had worse
In addition, gynecological symptoms were also present in female participants, which could have interfered in the final analysis in the present study although we assumed that vaginal delivery should have been similar in both groups. We recognize that one of the limitations was to not have had history of vaginal delivery. Additionally, we could not rule out that the other symptoms may have influenced the quality of life. It is relevant to mention that erectile dysfunction in HTLV-1 infected subjects is highly associated with urinary symptoms of overactive bladder (10).

Quality of life has been previously analyzed in HTLV-1 infected subjects with or without HAM/ TSP who present urinary symptoms. About 13.9\% of HTLV-1 carriers were found to have bad or very bad quality of life (15). These findings led to the conclusion that HTLV-1 infection, even in absence 
of HAM/TSP as long as urinary symptoms are present, negatively affects quality of life in affected individuals. However, limitations in the culture appropriateness of the questionnaire used (Ditrovie) could affect the efficacy of the evaluation instrument (16).

The advantage of SF-36 questionnaire used in this study compared to previously used surveys is that it is a multidimensional instrument that considers both individual perceptions and their health state. In addition, it encompasses various aspects of health in addition to being validated and translated into Portuguese.

Urinary symptoms can affect an individual's life both socially and economically. When investigating the impact of overactive bladder on work productivity, Sexton et al. (17) demonstrated that urinary symptoms were associated with low levels of work productivity. Although studies have shown a negative influence in the quality of life of HTLV-1 carriers who present urinary symptoms, a passive attitude is observed regarding the search for therapeutics that could soften this suffering. The findings here presented highlight the importance of health care professionals being aware of the psychosocial aspects of urinary symptoms in HTLV-1 infected subjects in order to improve quality of care, reinforcing the need to offer these patients alternatives for treatment aiming at improving overall quality of life and boosting self-esteem and dignity.

\section{CONCLUSIONS}

In conclusion, urinary symptoms negatively influence the quality of life of individuals infected by HTLV-1. Investments should be made in therapeutic resources in order to decrease the risks of urinary infection, and preservation of a functional urinary system. Steps should be taken to ease the psychosocial, physical and emotional limitations in affected individuals to improve quality of life.

\section{ACKNOWLEDGEMENTS}

We thank Érica de Castilho and Cristiano Sampaio for their contribution in the preparation of this manuscript.
This study was supported by the Brazilian National Research Council and the National Institute of Health (NIH) grant AI-079238.

\section{CONFLICT OF INTEREST}

None declared.

\section{REFERENCES}

1. Poiesz BJ, Ruscetti FW, Gazdar AF, Bunn PA, Minna JD, Gallo RC: Detection and isolation of type $C$ retrovirus particles from fresh and cultured lymphocytes of a patient with cutaneous T-celllymphoma. Proc Natl Acad Sci U S A. 1980; 77: 7415-9.

2. de Thé G, Bomford R: An HTLV-I vaccine: why, how, for whom? AIDS Res Hum Retroviruses. 1993; 9: 381-6.

3. Proietti FA, Carneiro-Proietti AB, Catalan-Soares BC, Murphy EL: Global epidemiology of HTLV-I infection and associated diseases. Oncogene. 2005; 24: 6058-68.

4. Catalan-Soares B, Carneiro-Proietti AB de F, Proietti FA: Heterogeneous geographic distribution of human T-cell lymphotropic viruses I and II (HTLV-I/II): serological screening prevalence rates in blood donors from large urban areas in Brazil. Cadernos de saúde pública / Ministério da Saúde, Fundação Oswaldo Cruz, Escola Nacional de Saúde Pública 2005; 21: 926-31.

5. Dourado I, Alcantara LC, Barreto ML, da Gloria Teixeira M, Galvão-Castro B: HTLV-I in the general population of Salvador, Brazil: a city with African ethnic and sociodemographic characteristics. J Acquir Immune Defic Syndr. 2003; 34: 527-31.

6. Cooper SA, van der Loeff MS, Taylor GP: The neurology of HTLV-1 infection. Pract Neurol. 2009; 9:16-26.

7. Araujo AQ, Silva MT: The HTLV-1 neurological complex. Lancet Neurol. 2006; 5: 1068-76.

8. Caskey MF, Morgan DJ, Porto AF, Giozza SP, Muniz AL, Orge GO, et al.: Clinical manifestations associated with HTLV type I infection: a cross-sectional study. AIDS Res Hum Retroviruses. 2007; 23: 365-71.

9. Castro NM, Freitas DM, Rodrigues W Jr, Muniz A, Oliveira P, Carvalho EM: Urodynamic features of the voiding dysfunction in HTLV-1 infected individuals. Int Braz J Urol. 2007; 33: 238-44; discussion 244-5.

10. Oliveira P, Castro NM, Muniz AL, Tanajura D, Brandão JC, Porto AF, et al.: Prevalence of erectile dysfunction in HTLV1 -infected patients and its association with overactive bladder. Urology. 2010; 75: 1100-3. 
11. Kluthcovsky AC, Takayanagui AM: Qualidade de Vida - Aspectos Conceituais. Revista Salus-Guanabara-PR. 2007; 1: 13-5.

12. Ciconelli RM, Ferraz MB, Santos W, et al.: Tradução para a língua portuguesa e validação do questionário genérico de avaliação de qualidade de vida SF-36 (Brasil SF-36). Revista brasileira de reumatologia. 1999; 39: 143-50.

13. Acquadro C, Kopp Z, Coyne KS, Corcos J, Tubaro A, Choo MS, et al.: Translating overactive bladder questionnaires in 14 languages. Urology. 2006; 67: 536-40. Erratum in: Urology. 2007; 69: 202. Oh, Seung June [added].

14. Diniz MS, Feldner PC, Castro RA, Sartori MG, Girão MJ: Impact of HTLV-I in quality of life and urogynecologic parameters of women with urinary incontinence. Eur J Obstet Gynecol Reprod Biol. 2009; 147: 230-3.

15. Castro NM, Rodrigues W Jr, Freitas DM, Muniz A, Oliveira P, Carvalho EM: Urinary symptoms associated with human T-cell lymphotropic virus type I infection: evidence of urinary manifestations inlarge group of HTLV-I carriers. Urology. 2007; 69: 813-8.
16. Ciconelli RM: Medidas de avaliação de qualidade de vida. Revista Brasileira de Reumatologia 2003; 43: 9-13.

17. Sexton CC, Coyne KS, Vats V, Kopp ZS, Irwin DE, Wagner $\mathrm{TH}$ : Impact of overactive bladder on work productivity in the United States: results from EpiLUTS. Am J Manag Care. 2009; 15: S98-S107.

\section{Correspondence address:} Edgar M. Carvalho, MD Serviço de Imunologia Hospital Universitário Professor Edgard Santos Universidade Federal da Bahia - UFBA Rua João das Botas, s/n, $5^{\circ}$ andar, Canela Salvador, BA, 40110-160, Brazil Fax: + $55713245-7110$ E-mail: edgar@ufba.br 